\title{
EFFECT OF DENTIN CONDITIONING AND EROSIVE COCA COLA CHALLENGE ON THE MICRO-SHEAR BOND STRENGTH AND SEM EVALUATION OF RESIN-MODIFIED GLASS-IONOMER CEMENT- IN VITRO STUDY
}

\author{
Nadia M. Zaghloul*
}

\begin{abstract}
Objective: This study was designed to evaluate the role of an erosive beverage, Coca cola, on the microshear bond strength of a nano-fill resin modified glass-ionomer cement to dentin, after different conditioning protocols, no conditioning, $\mathrm{GC}$ conditioner and $\mathrm{KN}$ primer.

Materials and Methods: The occlusal enamel of forty two third molar teeth was removed, exposing the coronal dentin. Thirty prepared teeth were randomly divided into three main groups $(n=10)$. Group 1, flat dentin surface was left unconditioned (control). Group 2, GC cavity conditioner was applied. Group 3, Ketac Nano Primer was applied. Three pieces were cut from a polyethylene micro-bore tygon tube, for each specimen. KN resin modified glass ionomer cement was applied. Each group was further distributed into two subgroups $(n=5)$. Subgroup i, teeth were immersed in artificial saliva (control). Subgroup ii, teeth were subjected to Coca Cola pH cycles. Each specimen was stressed in shear using a load cell of $5 \mathrm{KN}$ at a crosshead speed of $0.5 \mathrm{~mm} / \mathrm{min}$. The remaining 12 teeth were divided according to the previously mentioned grouping system, and observed using SEM.
\end{abstract}

Results: The data collected for $\mu$ SBS were subjected to two-way ANOVA test, followed by Tukey's post hoc test. Considering the dentin conditioning factor, with storage in artificial saliva; the control group revealed the least $\mu \mathrm{SBS}$ values, followed by the group conditioned with KNP and GC conditioning, respectively. Control group posses a significant decrease in the $\mu$ SBS compared to either GC or KNP groups. With Coke $\mathrm{pH}$ cycling; the control group revealed the least $\mu \mathrm{SBS}$ values, followed by KNP and GC conditioning, respectively. All the tested groups are significantly different from each other Considering the erosive $\mathrm{pH}$ cycling factor, all the teeth revealed significant decrease in the $\mu$ SBS values, when exposed to erosive Coke $\mathrm{pH}$ cycling. Most failure modes are adhesive, followed by mixed failures. The SEM examination showed a filler-free zone in the conditioned groups, with the greatest thickness with KNP. Cylindrical shaped resin tags, were observed when dentin is conditioned with KNP, whereas budding configuration is formed with GC conditioner. Smear layer has been completely removed with GC conditioner. Dentin conditioning

* Assistant Professor, Department of Operative Dentistry, Faculty of Dentistry, Mansoura University. 
with KNP revealed partial removal of smear layer with partial obliteration of dentinal tubules, while smear layer remains unaffected in case of control group. In groups stored in AS, there is intimate adaptation between the RMGIC and dentin, whereas the groups subjected to Coke erosive cycles showed variable degrees of separation at the RMGIC/dentin interface.

Conclusions: Dentin conditioning before RMGIC application is an essential step to improve bonding ability to dentin. Since Coca cola beverage revealed a deteriorating effect on bonding of RMGICs, evaluation of different acidic foodstuffs, acidic drinks and mouthwashes on the bonding efficiency of different types of glass-ionomer cements is required.

\section{INTRODUCTION}

The era of esthetic restorations was proceeded in the middle of the last century, since resin composite was introduced as an alternative to unfilled resin. Evolutions in esthetic restorations have resulted into two main categories of direct esthetic restorations, resin composites and glass ionomer cements (GIC). Since GICs were invented, these materials have undergone several developments in order to improve their physical and mechanical properties. ${ }^{1}$ It is well established that conventional GICs have inferior physical and mechanical properties, to resin composites. ${ }^{2-5}$ However, they have the main advantages of the potential of adhesion to tooth structures and sustained fluoride release. ${ }^{3} \mathrm{Al}-$ though bond strength is significantly inferior to that obtained with resin adhesives ${ }^{6}$, GICs are the only restorative materials adhere with reliable chemical bond to enamel and dentin with a noticeable disintegration resistant. ${ }^{7}$ Owing to the inferior physical and mechanical properties, conventional GICs significance, as permanent restorative materials, is mainly derived from their ability to replace dentin in sandwich restorations ${ }^{1}$, although a wide range of applications are indicated. ${ }^{8}$

Different strategies were followed to overcome shortcomings of conventional GICs..$^{9-11}$ One of these strategies is the resin-modified GIC, which has been introduced in the 1980s. Setting reaction of these materials is mainly acid-base reaction with an auxiliary photo-polymerization. ${ }^{12}$ Photo-polymerization is achieved by the addition of approximately 4.5 wt \% hydrophilic monomers, 2-hydroxyethylmethacrylate (HEMA), and a photo-initiator. ${ }^{13}$ This approach resulted in materials with improved proper- ties, compared with the conventional GIC, in terms of higher strengths, lower solubility, longer working time, shorter setting time, with improved esthetic appearance and translucency.

RMGICs still possess impaired mechanical properties, such as brittleness and strengths with inferior esthetics. ${ }^{14}$ Added to that, RMGICs have decreased fluoride release and increased creep compared with to conventional GICs. Nano-sized filler particles are incorporated into RMGIC, to overcome the existing flaws. Nanotechnology involves the use of materials which have the size in the range of $1-100 \mathrm{~nm}^{15,16}$, to improve the mechanical properties of dental restorative materials. ${ }^{17,18}$ In 2007, a nano-ionomer has been marketed. This material includes nano-fillers and nano-clusters of fluoroaluminosilicate glass, to improve physical and mechanical properties. ${ }^{16,19}$

Adhesion to both enamel and dentin is a prime request for successful restorations. Effective adhesion is achieved through obtaining an intimate contact between the tooth structures and restorative materials.$^{20}$ Following tooth preparation, smear layer is developed on the cut dentin surface, obturating the orifices of dentinal tubules with smear plugs and decreasing dentin permeability by up to $86 \%$. Smear layer is basically composed of pulverized hydroxyapatite and denatured collagen contaminated with micro-organisms, in an approximate thickness of 0.5-5 microns. ${ }^{21}$ This layer is an obstacle against the required intimate contact with the substrate. It does not provide a stable substrate for adhesion of the restorative material to tooth structures. By time smear layer gradually hydrolyzes under restorative materials results in bond failure.22 Therefore, the smear layer should be either modified or completely 
dissolved and removed. Dentin surface conditioning is performed to eliminate smear layer and surface contaminants which may reduce cement adhesion to tooth structures, following dentin cutting. There is a wide variety in dentin conditioners ${ }^{21,23-26}$, such as Polyacrylic acid and Aluminum chloride, used to improve the interaction between GICs and dentin surface, and in turn minimize bond failure at GIC/ tooth interface. Owing to its high molecular weight and ability to interact with the tooth substrates, polyacrylic acid (PAA) is highly recommended for dentin conditioning with GICs. ${ }^{13,24-26}$

Since GICs are inorganic materials, they are susceptible to acid erosion, but with decreased susceptibility for RMGICs. ${ }^{27-30}$ Several factors, involving frequent acidic foofstuffs exposure are responsible for the development of dental erosion. ${ }^{31-33}$ The high prevalence of dental erosions is principally associated with the widespread consumption of acidic beverages, specially coke. ${ }^{34}$ Several studies have been conducted to evaluate the erosive effects of different factors on the surface topography, chemical composition and behavior of direct and indirect restorative materials..$^{27-31,34-38}$
Several studies were conducted to evaluate the role of $\mathrm{pH}$ cycles on the validity of bond strength of resin composite restorations ${ }^{39-41}$, bond strength of restorations to eroded enamel and dentin ${ }^{42,43}$, but no or little information are available about the effect of $\mathrm{pH}$ cycling on the bonding of RMGICs to dentin. ${ }^{44}$

From the previous information a study designed to evaluate the role of an erosive beverage, Coca cola, on the micro-shear bond strength of nano-fill resin modified glass-ionomer cement to dentin, after different conditioning protocol, may be of interest. The null hypothesis is that none of the condition protocols or the erosive $\mathrm{pH}$ cycle affect the microshear bond strength ( $\mu$ SBS) of nano-fill resin modified glass-ionomer cement

\section{MATERIAL AND METHODS}

One type of resin modified glass-ionomer cement, Ketac Nano (KN) and two dentin conditioning protocols, GC Cavity Conditioner (CC), and Ketac Nano Primer (KNP), in addition to artificial saliva (AS) and Coca Cola beverage (Coke) were used. The materials' descriptions are listed in Table 1.

TABLE (1) Materials used in the study

\begin{tabular}{|c|c|c|}
\hline Material & Composition & Manufacturer \\
\hline KetacNano $(\mathrm{KN})$ & $\begin{array}{l}\text { Paste A: 40\%-50\% silane-treated glass, 20\%-30\% silane-treated zirconia, } \\
5 \%-15 \% \text { polyethylene glycol dimethacrylate (PEGDMA), 5\%-15\% silane- } \\
\text { treated silica, 1\%-15\% 2-hydroxyethyl methacrylate (HEMA), ,5\% glass } \\
\text { powder, ,5\% bisphenol-A diglycidyl ether dimethacrylate (BISGMA), ,1\% } \\
\text { triethylene glycol dimethacrylate (TEGDMA). } \\
\text { Paste B: } 40 \%-60 \% \text { silane-treated ceramic, } 20 \%-30 \% \text { copolymer of acrylic } \\
\text { and itaconic acids, } 10 \%-20 \% \text { water, } 1 \%-10 \% \text { HEMA. }\end{array}$ & $\begin{array}{l}\text { 3M-ESPE Dental products, } \\
\text { St. Paul, MN, USA }\end{array}$ \\
\hline $\begin{array}{l}\text { GC Cavity } \\
\text { Conditioner }(\mathrm{CC})\end{array}$ & $\begin{array}{l}20 \% \text { polyacrylic acid, } 77 \% \text { distilled water, } 3 \% \text { aluminum chloride hydrate, } \\
0.1 \% \text { food additive. }\end{array}$ & $\begin{array}{l}\text { GC corporation, Tokyo, } \\
\text { Japan }\end{array}$ \\
\hline $\begin{array}{l}\text { KetacNano } \\
\text { Primer (KNP) }\end{array}$ & $\begin{array}{l}50 \% \text { water, } 35 \% \text { Hydroxyethyl methacrylate, } 15 \% \text { copolymer of acrylic and } \\
\text { itaconic acids. }\end{array}$ & $\begin{array}{l}\text { 3M-ESPE Dental products, } \\
\text { St. Paul, MN, USA }\end{array}$ \\
\hline Artificial saliva & $\begin{array}{l}\text { prepared by mixing } 500 \mathrm{ml} \text { distilled water with } 1.2 \mathrm{~g} \text { potassium chloride, } \\
0.843 \mathrm{~g} \text { sodium chloride, } 0.051 \mathrm{~g} \text { magnesium chloride, } 20 \mathrm{ml} \text { stock solution } \\
\text { of tri-calcium phosphate } 1 \%(10.5 \mathrm{~g} \text { TCP and } 200 \mathrm{ml} \text { of } 1.0 \mathrm{M} \text { hydrochloric } \\
\text { acid) and Carboxy-methylcellulose. Sodium hydroxide }(0.05 \mathrm{M}) \text { was added } \\
\text { to the mixture to have a pH } 6.8\end{array}$ & $\begin{array}{l}\text { Prepared in Faculty of } \\
\text { Pharmacy, Mansura } \\
\text { University. }\end{array}$ \\
\hline Coca Cola & $\begin{array}{l}\text { Carbonated water, high fructose syrup, caramel color, phosphoric acid, } \\
\text { natural flavors, caffeine content: } 23 \mathrm{mg} / 8 \mathrm{fl} \mathrm{oz} \text {, very low sodium. } \mathrm{pH}=2.6 \\
\text { tritability }=120 \mathrm{ml}(0.1 \mathrm{~N} \mathrm{NaOH})\end{array}$ & $\begin{array}{l}\text { The Coca Cola company, } \\
\text { Egypt }\end{array}$ \\
\hline
\end{tabular}




\section{Teeth Selection:}

Permanent human maxillary and mandibular third molar teeth were collected from oral surgery department faculty of dentistry Mansoura University, to select a total of 42 teeth, free from either defects or restorations. The teeth were cleaned and scaled to remove calculus and soft tissue remnants, using sharp hand scalar (prima-Dent International, Francfurt, Germany). All the selected teeth were stored in $0.5 \%$ chloramine-T solution at $4 \pm 1^{\circ} \mathrm{C}$, for no more than one month.

\section{Tooth preparation:}

The selected teeth were mounted in acrylic resin (Acroston, under exclusive license of Acroston Dental Company-Cairo, Egypt) blocks for ease of handling. The occlusal enamel of each tooth was removed, exposing the coronal dentin, by cutting enamel perpendicular to the long axis of the tooth, using a low-speed diamond saw (Isomet,BuehlerLtd, LakeBluff, IL, USA) under copious water irrigation. The complete removal of enamel was verified using a stereomicroscope (Olympus, SZ61, Tokyo, Japan) at X40. The obtained dentin surface was then wet polished using a 600-grit silicon carbide paper in a clockwise motion for 20 seconds, to be followed by counter clockwise motion for another 20 seconds, to create a standardized smear layer. Gross particles were removed using an ultrasonic bath in distilled water for 2 minutes. Dentin surfaces were then dried before conditioning.

\section{Dentin conditioning}

Thirty prepared teeth were randomly divided into three main groups $(n=10)$ depending on the dentin conditioer used. In group 1, flat dentin surface was left unconditioned, to act as a negative control with the smear layer left intact. In group 2, using a flexible applicator, GC cavity conditioner was applied to dentin surface and left for 30 seconds. The conditioner was washed out for 10 seconds, using an oil free copious water spray, and then the dentin surface was blot dried with a sterile cotton pellet, to leave dentin surface visibly moist. In group 3, Ketac Nano Primer was applied to the flat dentin surface for 30 seconds using a flexible microbrush. The primer was air dried for 10 seconds and photo-cured for 10 seconds, using LED unite with a light intensity of $800 \mathrm{~mW} / \mathrm{cm}^{2}$ (LEDition, Ivoclar Vivadent, Germany).

\section{Restoration Placement}

After dentin conditioning, three pieces were cut from a polyethylene micro-bore tygon tube (Norton Performance Plastic Co, USA), with $2 \mathrm{~mm}$ height and $0.9 \pm 0.1 \mathrm{~mm}$ internal diameter, for each specimen. Resin modified glass ionomer cement was activated, mixed for 10 seconds and applied according to the manufacturer's instructions. Each tygon tube was grasped with cotton forceps to control fixation of the tube onto the flat dentin. The mixed material was carefully syringed into one side of the tygon tube with the capsule applicator and gently packed tell the material slightly extruded from the other side of the tube. Then the filled tube was applied to a delineated site on the dentin conditioned surface with slight pressure, then light-cured for 40 seconds. Another two tubes were applied in delineated sites onto the same conditioned dentin surface, to obtain three readings from each surface. Excess materials and flashes were removed with a sharp \#15 scalpel blade. All specimens were stored in distelled water at $37 \pm 1^{\circ} \mathrm{C}$ in an incubator for 7 days before exposure to $\mathrm{pH}$ cycyles.

\section{Erosive Challenge}

Each group was further distributed into two subgroups relative to the immersion regimens. In subgroup $i$, five teeth from each group were immersed in artificial saliva during the experimental period (control). In subgroup ii, five restorations from each group were placed in a plastic air tight container, which was filled with $25 \mathrm{ml}$ Coke solution per specimen for 5 minutes. ${ }^{45}$ Fresh Coke was used 
for each immersion. A high immersion regime in which the teeth were subjected to ten immersions per day evenly distributed over 13.30 hour's period daily, for seven days. ${ }^{46}$ It should be recalled after each immersion in Coke, the specimens were maintained in artificial saliva at $37 \pm 1^{\circ} \mathrm{C}$.

\section{Micro-shear Bond Strength Test ( $\mu \mathrm{SBS})$ :}

Each specimen with the three bonded microcylinders was fixed into the lower compartment of the universal testing machine (Instron 3382, Canton, MA, USA). A loop of orthodontic stainless steel wire, with a diameter of $0.2 \mathrm{~mm}$, was wrapped around one bonded micro-cylinder making contact through half of its circumference and then gently flushed against the restoration/dentine interface. The specimen was aligned with the loading axis of the upper movable compartment of the testing machine. Each specimen was stressed in shear using a load cell of $5 \mathrm{KN}$ at a crosshead speed of $0.5 \mathrm{~mm} / \mathrm{min}$. The shear force at failure of each micro-cylinder was recorded and converted to shear stress in MPa units using computer software (NexygenMT Lloyd Instruments, Fareham, UK).

\section{Mode of failure analysis}

The debonded specimens were viewed under a stereomicroscope at $45 \mathrm{x}$, in order to evaluate the fracture patterns. Failure modes were classified into, adhesive failure when fracture occurred at the dentin/material interface. Cohesive failure when failures within the dentin surface or within the material itself. Mixed failure, when failure present partly in an adhesive and partly in a cohesive modes.

\section{Micro-morphological analysis}

For micro-morphological analysis, the remaining 12 teeth were divided according to the previously mentioned grouping system. After dentin conditioning, a cubic RMGIC build up, of $2 \mathrm{~mm}$ dimensions was performed on each tooth using a plastic mold. Each tooth is sectioned vertically through the restoration/dentine surface interface and the cut surface is wet polished with serial (600-4000) grit silicon carbide papers (Microcut ${ }^{\mathrm{TM}}$ Buehler, Lake Bluff, IL, USA), followed by lapping with a polishing cloth with 6,3 and $1 \mu \mathrm{m}$ diamond pastes (Diamat, pace Technologies, Tuscon, AZ, USA). Specimens were ultrasonically cleaned in distilled water and then the bonded interface is etched with $10 \%$ orthophosphoric acid solution for 10 seconds, followed by $5 \%$ NaoCL for $20 \mathrm{~min}$. The acid-base resistant layer is observed using Scanning Electron Microscopy (SEM).

\section{RESULTS}

\section{Microshear bond strength ( $\mu$ SBS)}

Kolmgorov-Smirnov test revealed normal distribution of values in each group. The datacollected for micro-shear bond strength were subjected to two-way ANOVA test, to detect significance among the tested variables, then Tukey's post hoc test was carried out to detect significance between each two groups. Both the dentin conditioning and erosive $\mathrm{pH}$ cycle revealed statistical significance $(\mathrm{p}<0.0001)$ Table 2. The means and slandered deviations of $\mu \mathrm{SBS}$ are described in table 3. Considering the dentin conditioning factor, when teeth were stored in artificial saliva; the control group, where dentin surface was left without conditioning, revealed the least $\mu$ SBS values (4.5482), to be followed by the group conditioned with KNP (7.2569), with the highest values recorded with group of GC dentin conditioning (7.6605). Control group posses a significant decrease in the $\mu \mathrm{SBS}$ compared to either $\mathrm{GC}$ or KNP groups, but there is no significant difference between the last two groups. When teeth were exposed to Coke $\mathrm{pH}$ cycling; the control group revealed the least $\mu \mathrm{SBS}$ values, as well (1.5617), to be followed by the group conditioned with KNP (3.5795), with the highest values recorded with group of GC dentin conditioning (5.3802). Control group posses a significant decrease in the $\mu \mathrm{SBS}$ 
compared to GC conditione and KNP groups. Also there is a significant difference between the KNP group and GC conditioner. Considering the erosive $\mathrm{pH}$ cycling factor, all the teeth revealed significant decrease in the $\mu \mathrm{SBS}$ values, when exposed to erosive Coke $\mathrm{pH}$ cycling, in comparison with storage in artificial saliva.

\section{Failure mode observation.}

Most fractured surfaces failed in the adhesive mode, followed by the mixed mode of failures, with a few cohesive failures in RMGIC. It was evident that the highest percent of adhesive failure was present in the non-conditioned groups, stored in AS or subjected to Coke pH cycles $(80,70 \%)$, while the lowest values of adhesive failure are recorded with Coke pH cyling of both GC and KNP conditioning groups $(50 \%)$. When dentin conditioned with GC in both groups or conditioned with KNP and subjected to Coke $\mathrm{pH}$ cycles, the highest values of mixed failure are recorded $(40 \%)$, with the lowest value with control group stored in AS, table 4 and figure 1 .

TABLE (2) Two-Way ANOVA test Results (Both factors significantly influenced the results)

\begin{tabular}{|l|r|r|r|r|r|}
\hline Dependent Variable: var & Type III Sum of Squares & df & Mean Square & F & Sig. \\
\hline Source & $395.408^{\mathrm{a}}$ & 5 & 79.082 & 215.979 & .000 \\
\hline Corrected Model & 2248.040 & 1 & 2248.040 & 6139.606 & .000 \\
\hline Intercept & 188.087 & 2 & 94.044 & 256.842 & .000 \\
\hline Cond & 200.000 & 1 & 200.000 & 546.218 & .000 \\
\hline Eros & 7.321 & 2 & 3.660 & 9.997 & .000 \\
\hline Cond $*$ Eros & 30.757 & 84 & .366 & & \\
\hline Error & 2674.205 & 90 & & & \\
\hline Total & 426.165 & 89 & & & \\
\hline Corrected Total & \multicolumn{2}{|c|}{} & & & \\
\hline a. R Squared $=.928$ (Adjusted R Squared $=.924)$ & & & \\
\hline
\end{tabular}

TABLE (3) Tukey post Hoc Multiple comparison test results of dentin conditioning and pH cycling

\begin{tabular}{|c|c|c|c|c|c|c|c|c|}
\hline & \multirow[t]{2}{*}{$\mathrm{N}$} & \multirow[t]{2}{*}{ Mean } & \multirow[t]{2}{*}{ Std. Deviation } & \multirow[t]{2}{*}{$\begin{array}{l}\text { Std. } \\
\text { Error }\end{array}$} & \multicolumn{2}{|c|}{$\begin{array}{l}\text { 95\% Confidence Interval for } \\
\text { Mean }\end{array}$} & \multirow[t]{2}{*}{ Minimum } & \multirow[t]{2}{*}{ Maximum } \\
\hline & & & & & Lower Bound & Upper Bound & & \\
\hline No_Sal & 15 & $4.5482^{\mathrm{c}}$ & .46489 & .12004 & 4.2908 & 4.8056 & 3.80 & 5.22 \\
\hline No_Coke & 15 & $1.5617^{\mathrm{e}}$ & .48754 & .12588 & 1.2917 & 1.8317 & .78 & 2.31 \\
\hline Cc_Sal & 15 & $7.6605^{\mathrm{a}}$ & .76053 & .19637 & 7.2393 & 8.0816 & 6.00 & 8.54 \\
\hline CC_Coke & 15 & $5.3802^{b}$ & .78603 & .20295 & 4.9449 & 5.8155 & 4.34 & 7.00 \\
\hline Kn_Sal & 15 & $7.2569^{\mathrm{a}}$ & .46416 & .11985 & 6.9999 & 7.5140 & 6.54 & 8.04 \\
\hline Kn_Coke & 15 & $3.5795^{\mathrm{d}}$ & .57568 & .14864 & 3.2607 & 3.8983 & 2.68 & 4.39 \\
\hline Total & 90 & 4.9978 & 2.18823 & .23066 & 4.5395 & 5.4561 & .78 & 8.54 \\
\hline
\end{tabular}


TABLE (4) Percentage of fracture modes

\begin{tabular}{|l|l|c|c|c|c|}
\hline \multicolumn{2}{|l|}{ Fracture modes } & Adhesive & Cohesive D & Cohesive M & Mixed \\
\hline \multirow{4}{*}{ No conditioning } & Artifial saliva & 80 & - & 10 & 10 \\
\cline { 2 - 6 } & Coke & 70 & - & - & 40 \\
\hline \multirow{3}{*}{ GC conditioner } & Artifial saliva & 60 & - & 10 & 40 \\
\cline { 2 - 6 } & Coke & 50 & - & 10 & 30 \\
\hline \multirow{2}{*}{ KN primer } & Artifial saliva & 60 & - & 10 & 40 \\
\cline { 2 - 6 } & Coke & 50 & & & 4 \\
\hline
\end{tabular}

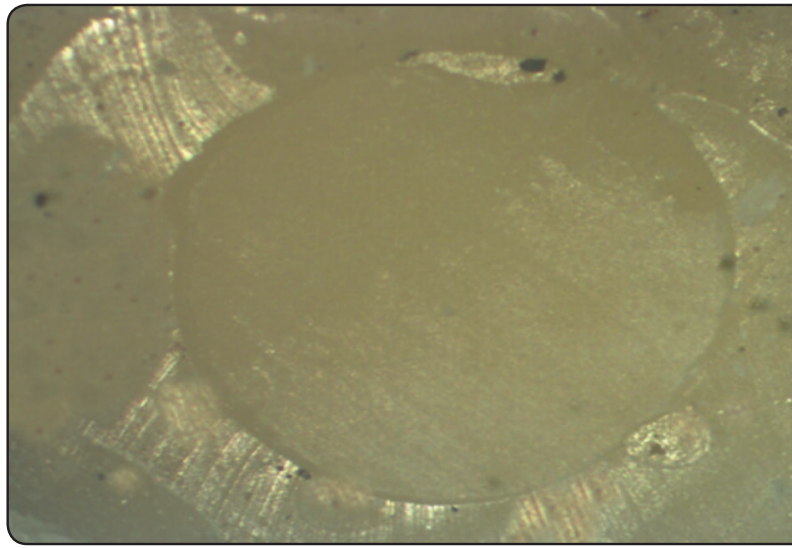

Streomicroscopic photomicrograph of debonded specimen of control group stored in artificial saliva showing adhesive failure mode

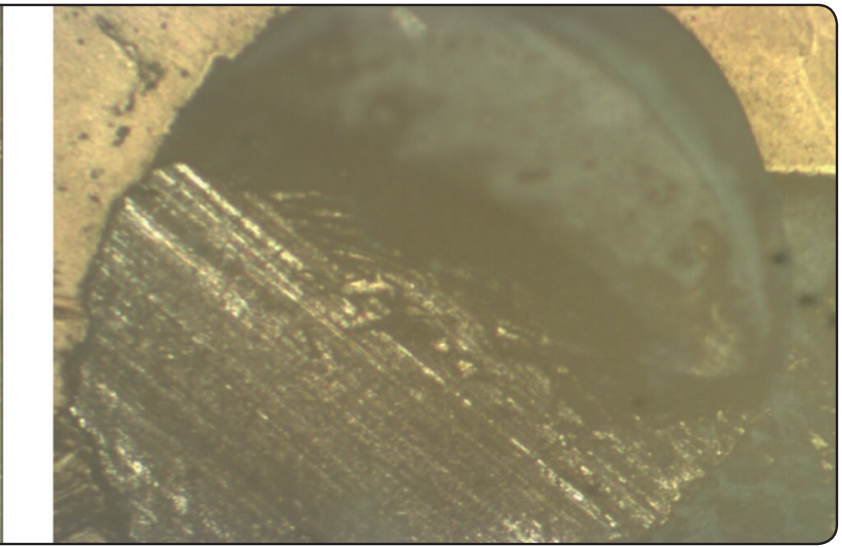

Streomicroscopic photomicrograph of debonded specimen of GC conditioned group subjected to erosive $\mathrm{pH}$ cycle showing mixed failure mode

Fig. (1) Composed figure showing the failure modes

\section{Micomorphological observations}

The scanning electron micrographs illustrate the ultra-structural observations of the RMGIC/dentine interfaces in Figs 2-4. All the specimens revealed the presence of RMGIC/dentin ion exchange layer, acid resistant layer, in all groups. In the conditioned groups, a filler-free zone is observed, with the greatest thickness noticed in specimens conditioned with KNP. Penetration of the material matrix into demineralized dentin is manifested as cylindrical shaped resin tags, when dentin is conditioned with KNP, whereas budding configuration is formed after conditioning with GC conditioner. Smear layer has been removed with opening of the dentinal tubules when dentin is conditioned with GC conditioner. Dentin conditioning with KNP revealed partial removal of smear layer with partial obliteration of dentinal tubules with smear blugs, while smear layer remains unaffected in case of application of RMGIC without conditioning. In groups stored in $\mathrm{AS}$, the observations of RMGIC/dentin interfaces indicated intimate adaptation between the RMGIC and dentin after acid-base challenge, whereas the groups subjected to Coke erosive cycles showed variable degrees of separation, adhesion failure, at the RMGIC/dentin interface. 


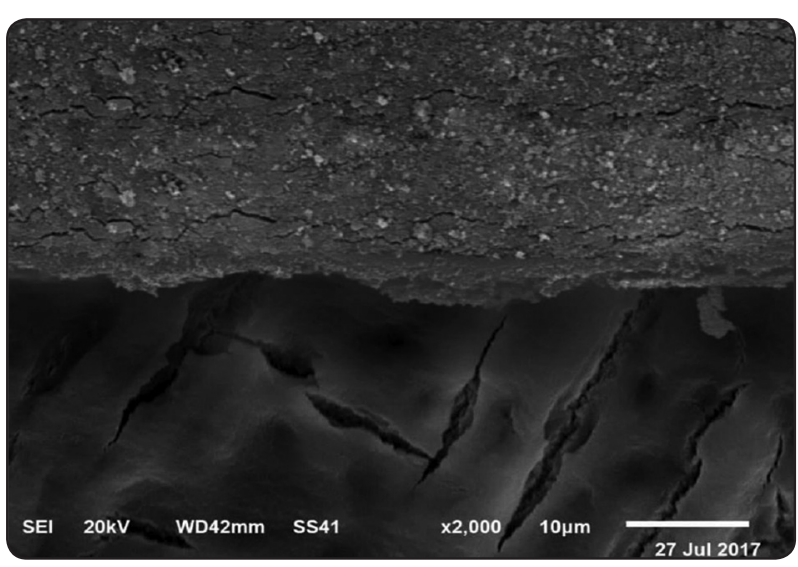

Fig (2) SEM photomicrograph of KN/dentin interface, without conditioning after storage in AS. Thick smear layer with obliterated dentinal tubules. There is intimate contact at the RMGIC/dentin interface. Absence of filler free zone and resin tags.

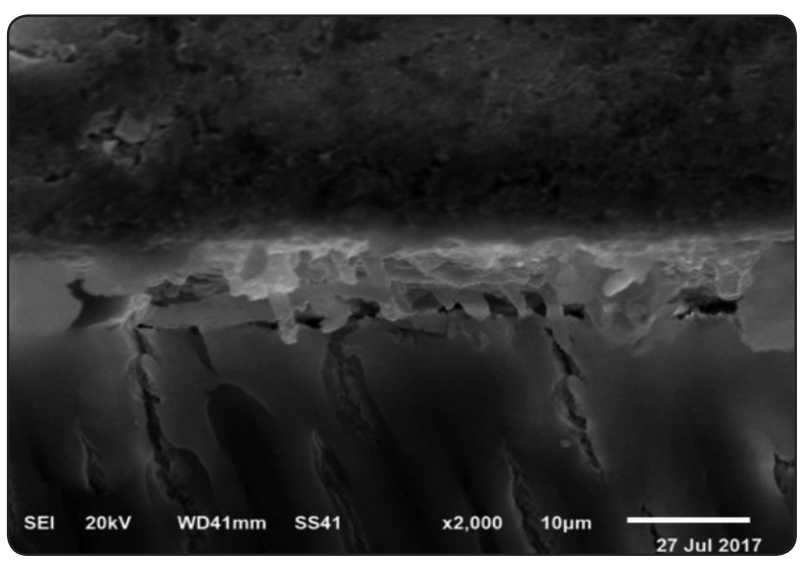

\section{DISCUSSION}

The successful restorations depend mainly on the efficient, long lasting adhesion to dentin substrate. Several tests have been utilized to assess the bond performance of restorative systems. Shear bond strength test is one of the most widely used methods to evaluate bond ability of adhesives to either enamel or dentin. In particular glass ionomer cements have low bond strength, making other tests may be difficult to be applied. ${ }^{23}$ Lately, micro-shear bond strength test has been favored as an adjusted method for evaluation of bonding to dentin, especially when glass-ionomer cements are tested. ${ }^{47}$ It has been suggested that tested cross sectional area has a great impact on the shear bond strength values,

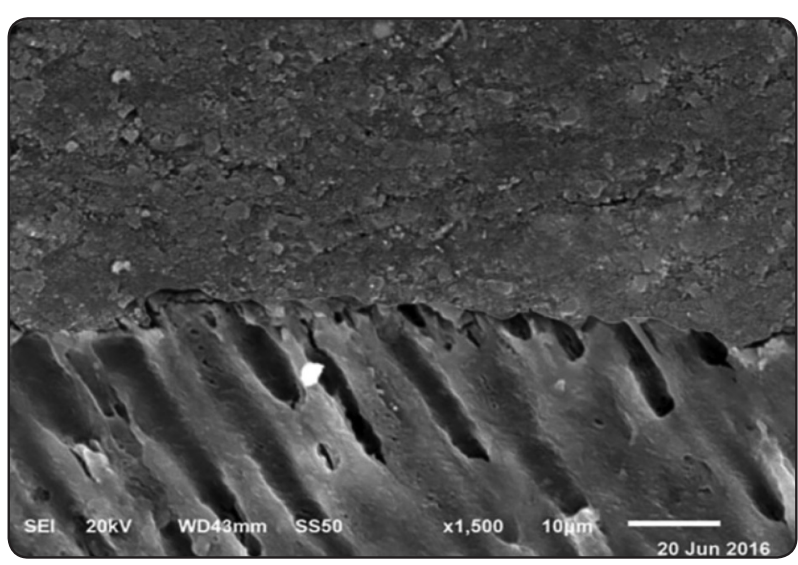

Fig (3) SEM photomicrograph of $\mathrm{KN} /$ dentin interface, conditioned with GC conditioner, after storage in AS. Complete removal of smear layer with opened dentinal tubules. There is intimate contact at the RMGIC/dentin interface, with resin few budding resin tags.

Fig (4) SEM photomicrograph of $\mathrm{KN} /$ dentin interface, conditioned with KNP after subjected to Coke $\mathrm{pH}$ cycles. Partial removed Smear layer and smear blugs is noticed. There is thin fill-free zone with cylindrical resin tags. RMGIC/dentin interface revealed partial separation.

as larger cross-sectional area usually result in flaws and irregularities at the cement-dentin interface with inaccurate results. ${ }^{48}$

RMGICs bond to tooth structured via two mechamisms, a chemical and micromechanical bonds. Chemically, the carboxyl groups, anions, of the polyalkenoic acid chains bond ionically to dentin, through hydrogen bonds with calcium ions, cations, in hydroxiapatite. Micromechanically, through resin infiltration into prepared tooth structures. ${ }^{49}$ Although the existence of smear layer could hamper bonding to dentin ${ }^{50}$, the low $\mu \mathrm{SBS}$ of $\mathrm{KN}$ glass ionomer with the intact smear layer is mainly gained through polyacrylic acid present in the material, which acts as a mild dentin conditioner. In addition, 
calcium ions present in the smear layer may provide chemical bonding with the polyalkenoic acid chains in the RMGIC. Also, prospective micromechanical retention via the dentin irregularities produced during specimen preparation is valuable..$^{51}$

An intimate contact between glass-ionomer cement and tooth structure is of a paramount importance for an efficient adhesion. Dentin surface conditioning is recommended to obtain the intimate contact and improve bonding to dentin, as dentin conditioners can remove the loosely attached smear layer and partially demineralize dentin. Partial demineralization of dentin provides increased wetting that enhance chemical interaction of the polyalkenoic acid with residual hydroxyapatite. The increased surface area and micro-porosities of the conditioned dentin, in addition to exposure of collagen could enhance additional micromechanical retention. ${ }^{23,50-52}$ The results of the present study are aligned with this discussion, as the teeth left without conditioning showed significantly impaired $\mu \mathrm{SBS}$ values in comparison with teeth conditioned with either GC conditioner or KNP. SEM examination of the unconditioned dentin/RMGIC interface, in this study, revealed presence of a thick smear layer to which the material is adhered, with absence of resin tag formation. This study is in agreement with some studies who reported that dentin conditioning does improve bond strength and provide better adhesion to tooth structures. ${ }^{53-55} \mathrm{On}$ the other hand, other researchers concluded that dentin conditioning prior to restoration is not a beneficial step as the acidic nature of glass ionomer can partially dissolve smear layer. $^{24,56}$

The results of the present study revealed that both conditioning materials have the same benefits of improving adhesion to dentin, in term of comparable $\mu$ SBS values, although GC conditioner revealed insignificantly higher values. Regarding to GC conditioner, the increase in the polyacrylic acid concentration, with washing step, completely removes the smear layer; allowing good wetting of the partially polymerized dentin. Surface demineralization and increased wetting of dentin can facilitate HEMA monomer, present in RMGIC, penetration. ${ }^{57}$ Another reason for improved $\mu \mathrm{SBS}$ when GC conditioner was used is the incorporation of aluminum chloride which is thought to stabilize collagen during demineralization, increasing infiltration of resin into the demineralized dentin. ${ }^{58}$ Morover, although the presence of high concentration of the hydrophilic monomer, HEMA, in the $\mathrm{KN}$ primer does provide good wettability of the hydrophilic dentin, it may produce incomplete polymerization and increase permeability, resulted in debonding..$^{59}$ Dentin conditioning with the $20 \%$ concentration polyacrylic acid followed by dentin washing, could completely remove smear layer, which is the case in the present study. SEM examination of dentin conditioning with GC primer revealed complete removal of smear layer, while $\mathrm{KN}$ primer revealed partial removal of smear layer and smear blugs.

Although the oral environment is the ultimate testing conditions to predict the restorations behavior, in vitro models are very important to give an idea about mechanisms of biodegradation. In the present study a dynamic $\mathrm{pH}$ cycle model was utilized to simulate the clinical conditions, as the consumed foodstuffs and drinks become in direct impinging with the tooth for just seconds or minutes before washing off by saliva. ${ }^{60}$

Concerning the effect of Coke $\mathrm{pH}$ cycling, $\mu \mathrm{SBS}$ of the three test groups, subjected to different conditioning protocols, showed significant decrease when teeth were exposed to Coke challenge. Success of restorations is the responsibility of their behavior under different oral environmental conditions. The $\mathrm{pH}$ fluctuation is one of the serious oral environmental conditions that deteriorate restorations. As Coke drinks are based on phosphoric acid content with an acidic $\mathrm{pH}$ of 2.5-3.0, Coke could induce erosive 
effect on dentin peripheral to the bonded area, through ionic interaction with calcium ions in the hydroxyapatite. ${ }^{61,62}$ This partially demineralized dentin may result in deterioration of bonding of RMGIC to dentin. Another effect of the low pH Coke is the selective acid attack and dissolution of the poly-salts formed by anionic/cationic ionic interaction of poly-acid with calcium contents of bonded dentin, which could result in degradation of chemical adhesion of RMGIC to dentin. ${ }^{63}$

In addition, the presence of the hydrophilic HEMA, Bis-GMA and TEGDMA monomers in the RMGIC may adversely affect bonding to dentin. The hydrophilic HEMA may produce incomplete polymerization with increased water permeability at the bonding interface as well the restoration. Water attraction by HEMA induce hydrolytic degradation, under the acidic condition at the restoration/tooth structure interface..$^{59}$ The polyalkanoate and HEMA polymer are entangled with each other rather than chemically incorporated. The existence of the resin polymer may be sufficient to protect the matrix against foodstuffs and drinks with $\mathrm{pH}$ of 5 , but not a case in acidic drinks of $\mathrm{pH}$ values less than $4{ }^{64}$ The ester radicals in the dimethacylate monomers, Bis-GMA and TEGDMA, hydrolyse in low $\mathrm{pH}$, decreasing bonding capacity. ${ }^{65}$ Narsimha $\mathrm{VV}^{36}$ concluded that prolonged exposure to acidic media, Coca cola soft drink, adversely affect the adaptation of resin modified glass ionomer to cavity walls. Also, the frequency of exposure to Coca Cola is directly proportional to the marginal adaptation. SEM examination of the restoration/dentin interface of samples subjected to erosive challenge showed signs of separation at the interface, indicating bond failure due to Coca Cola challenge. The modes of failure in all the groups are mostly adhesive in nature, followed by mixed failures, indicating that the material strength has exceeded the bond strength at the restoration/tooth interface. The null hypothesis was rejected, as both the dentin conditioning and the erosive challenges significantly affect $\mu$ SBS of resin modified glass ionomer cement.

\section{CONCLUSIONS}

Considering the in Vitro study entry and the results obtained in this study, it can be concluded that: Dentin conditioning before RMGIC application is an essential step to improve bond ability to dentin. Since Coca cola beverage revealed a deteriorating effect on bonding of RMGICs, evaluation of different acidic foodstuffs, acidic drinks and mouthwashes on the bonding efficiency of different types of glass-ionomer cements is required.

\section{REFERENCES}

1. Davidson CL. Advances in glass-ionomer cements. J Appl Oral Sci. 2006;14:3-9.

2. Xie D, Brantley WA, Culbertson BM, Wang G. Mechanical properties and microstructures of glass-ionomer cements. Dent Mater. 2000;16:129-38.

3. Baig MS, Fleming GJP. Conventional glass-ionomer materials: A review of the developments in glass powder, polyacid liquid and the strategies of reinforcement. J Dent. 2015;43:897-912.

4. Nicholson J, Czarnecka B. 6 - Conventional glass-ionomer cements. Materials for the Direct Restoration of Teeth. 2016;107-36.

5. Yap AUJ, Cheang P. Physico-mechanical properties of a fast-set highly viscous GIC restorative.J Oral Rehab. 2003;30:1-8.

6. Mount GJ. Glass-ionomer cements: past, present and future. Oper Dent. 1994;19:82-90.

7. Akinmade AO, Nicholson JW. Glass-ionomer cements as adhesives. Part I: Fundamental aspects and their clinical relevance. J. Mater. Sci.: Mater. Med. 1993;4:95-101.

8. Murdoch-Kinch CA, McLean ME. Minimally invasive dentistry. J Am Dent Assoc. 2003;134:87-95.

9. Moshaverinia A., Roohpour N., Chee W.W.L., Schricker S.R. A review of powder modifications in conventional glass-ionomer dental cements. J. Mater. Chem. 2011;21:1319-28.

10. Moshaverinia A, Ansari S, Moshaverinia M, Roohpour N, Darr JA, Rehman IU. Effects of incorporation of hydroxyapatite and fluoroapatite nanobioceramics into conventional glass ionomer cements (GIC). Acta Biomater. 2008;4:432-40.

11. Moshaverinia A, Ansari S, Movasaghi Z, Billington RW, Darr JA, Rehman IU. Modification of conventional glassionomer cements with $\mathrm{N}$-vinylpyrrolidone containing polyacids, nano-hydroxy and fluoroapatite to improve mechanical properties. Dent Mater. 2008;24:1381-90. 
12. Korkmaz Y., Gurgan S., Firat E., Nathanson D. Shear bond strength of three different nano-restorative materials to dentin. Oper. Dent. 2010;35:50-7.

13. Imbery T.A., Namboodiri A., Duncan A., Amos R., Best A.M., Moon P.C. Evaluating dentin surface treatments for resin-modified glass ionomer restorative materials. Oper. Dent. 2013;38:429-38.

14. McCabe JF. Resin-modified glass-ionomers. Biomaterials 1998; 19: 521-7.

15. Hannig M, Hannig C. Nanomaterials in preventive dentistry. Nat Nanotechnol. 2010; 5:565-9.

16. Khurshid Z., Zafar M., Qasim S., Shahab S., Naseem M., AbuReqaiba A. Advances in nanotechnology for restorative dentistry. Materials. 2015;8:717-31.

17. Terry DA. Direct applications of a nanocomposite resin system: Part 1--The evolution of contemporary composite materials. Pract Proced Aesthet Dent. 2004;16:417-22.

18. Chen MH. Update on dental nanocomposites. J Dent Res. 2010;89:549-60.

19. De Caluwé T, Vercruysse CW, Fraeyman S, Verbeeck RM. The influence of particle size and fluorine content of aluminosilicate glass on the glass ionomer cement properties. Dent Mater. 2014;30:1029-38.

20. Mazaheri R, Pishevar L, Shichani AV, Geravandi S. Effect of different cavity conditioners on microleakage of glass ionomer cement with a high viscosity in primary teeth. Dental research journal 2015;12:337.

21. Jena A, Hegde J. Bond Strength of Light Activated Glass Ionomer With Different Conditioners on Human Dentin. International Journal of Technology Enhancements and Emerging Engineering Research 2012;1:26-9.

22. Yilmaz Y, Gurbuz T, Kocogullari M. The influence of various conditioner agents on the interdiffusion zone and microleakage of a glass lonomer cement with a high viscosity in primary teeth. Oper dent 2004;30:105-12.

23. Di Nicoló R, Shintome LK, Myaki SI, Nagayassu MP. Bond strength of resin modified glass ionomer cement to primary dentin after cutting with different bur types and dentin conditioning. J of Appl Oral Scie. 2007;15:459-64.

24. Tanumiharja M, Burrow M, Tyas M. Microtensile bond strengths of glass ionomer (polyalkenoate) cements to dentine using four conditioners. J Dent. 2000;28:361-6.

25. Tyas MJ, Burrow M. Adhesive restorative materials: a review. Aust Dent J 2004;49:112-121.

26. Tyas MJ. The effect of dentine conditioning with polyacrylic acid on the clinical performance of glass ionomer cement. Aust dent j 1993;38:46-8.

27. Francisconi LF, Honório HM, Rios D, Magalhães AC, Machado MAAM, and M, Buzalaf AR. Effect of Erosive
$\mathrm{pH}$ Cycling on Different Restorative Materials and on Enamel Restored with These Materials Oper Dent. 2008; 33:203-8.

28. Honorio HM, Rios D, Francisconi LF, Magalhaes AC, Machado MAAM, Buzalaf MAR. Effect of prolonged erosive $\mathrm{pH}$ cycling on different restorative materials. J Oral Rehab. 2008;35:947-53.

29. da Silva A, Rapôso N, Gomes I, Gonçalves L, Paschoal $M$. In vitro quantitative comparison of erosive potential of infant mouthwashes on glass ionomer cement. J Clin Exp Dent. 2018;10:e206-11.

30. de Queiroza MMV, Shibasakia PAN, Limab MJP, de Araújob RPC, Foxtonc RM, Cavalcantiab AN. Effect of erosion and methods for its control on the surface roughness of composite resin. J Oral Sci. 2017;32:88-93

31. Machado C, Lacefield W, Catledge A. Human enamel nanohardness, elastic modulus and surface integrity after beverage contact. Braz Dent J 2008;19:68-72.

32. Ulusoy C, Mujdeci A, Gokay O. The effect of herbal teas on the shear bond strength of orthodontic brackets. Eur J Orthod 2009;31:385-9.

33. Mandel L. Dental erosion due to wine consumption. J Am Dent Assoc. 2005;136:71-75.

34. Khamverdi Z, Mohammad V, Shermin A, Mohammad H. Effect of a Common Diet and Regular Beverage on Enamel Erosion in Various Temperatures: An In-Vitro Study. Journ Dent Teheran 2013;10:411-6.

35. Andreea B, Cristina M, Melinda S. The behaviour of composites, glass ionomers and compomers in erosive conditions - in vitro study. Acta Medica Marisiensis. 2014;60:200-3

36. Poggio C, Vialba L, Marchioni R, Colombo M, Pietrocola G. Esthetic restorative materials and glass ionomer cements: Influence of acidic drink exposure on bacterial adhesion. Eur J Dent. 2018;12:204-9.

37. Erdemir U, Yildiz E, Eren MM, Ozel S. Surface hardness of different restorative materials after long-term immersion in sports and energy drinks. Dent Mater J. 2012;31:729-36.

38. Tofan N, Andrian S, Stoleriu S, Nica I, Moldovanu A, Topoliceanu C, Solomon O, Pancu G. The Assessment of the Surface Status Following the Action of Some Acidic Beverages on Indirect Restorative Materials. MATERIALE PLASTICE.2018;55:129-35.

39. Machado CM, Zamuner AC, Modena KC, Ishikiriama SK, Wang L.How erosive drinks and enzyme inhibitors impact bond strength to dentin. Braz Oral Res. 2015;29:1-7.

40. Pedrosaa VO, Floriob FM, Turssic CP, Lucisano F, Amarald B, Bastinge RT, Francaf FMG. Influence of $\mathrm{pH} \mathrm{Cy-}$ cling on the Microtensile Bond Strength of Self-etching 
Adhesives Containing MDPB and Fluoride to Dentin and Microhardness of Enamel and Dentin Adjacent to Restorations. J Adhes Dent 2012; 14: 525-34.

41. Cruz JB, Bonini G, Lenzi TL, Imparato JC, Raggio DP. Bonding stability of adhesive systems to eroded dentin. Braz Oral Res. 2015;29:1-6

42. Casas-Apayco LC, Dreibi VM, Hipolito AC, Graeff MSZ, Rios D, Magalhaes ES AC, Buzalaf MAR, Wang L. Erosive cola-based drinks affect the bonding to enamel surface: an in vitro study. J Appl Oral Sci. 2014;22:434-41.

43. Nahsan FPS, Michielin MB, da Silva LM, Machdo CM, Andrade AM, Franciscon PAS, Mondelli RFL, Wang L. Bond strength of a resin composite and a resin-modified glass-ionomer cement associated or not with chlorhexidine to eroded dentin. Braz Dent Sci. 2015;18:31-7.

44. Narsimha VV. Effect of Cola on Surface Microhardness and Marginal Integrity of Resin Modified Glass Ionomer and Compomer Restoration - An in vitro Study. People's Journal of Scientific Research. 2011;4:34-40.

45. Maupomé G, Díez-de-Bonilla J, Torres-Villaseñor G, Andrade-Delgado LC, Castaño VM: In vitro quantitative assessment of enamel microhardness after exposure to eroding immersion in a cola drink. Caries Research, 1998;32:148-53.

46. Staninec M, Holt M: Bonding of amalgam to tooth structure: Tensile adhesion and microleakage tests. The Journal of Prosthetic Dentistry, 1988;59:397-402.

47. Münchow EA, Bossardi M, Priebe TC, Valente LL, Zanchi $\mathrm{CH}$, Ogliari FA, et al. Microtensile versus microshear bond strength between dental adhesives and the dentin substrate. International Journal of Adhesion and Adhesives 2013;46:95-9.

48. Phrukkanon S, Burrow M, Tyas M. Effect of cross-sectional surface area on bond strengths between resin and dentin. Dent mat. 1998;14:120-8.

49. Oliveira SS, Pugach MK, Hilton JF, Watanabe LG, Marshall SJ, Marshall GW, Jr. The influence of the dentin smear layer on adhesion: A self-etching primer vs. a totaletch system. Dent Mater. 2003;19:758-67.

50. Wang L, Sakai VT, Kawai ES, Buzalaf MA, Atta MT. Effect of adhesive systems associated with resin-modified glass ionomer cements. J Oral Rehab. 2006;33:110-6.

51. Powis DR, Folleras T, Merson SA, Wilson AD. Improved adhesion of glass-ionomer cement to dentin and enamel. J Dental Res. 1982; 6:1416-22.

52. Poggio C. Effects of dentin surface treatments on shear bond strength of glass-ionomer cements. Annali di stomatologia 2014;5:15.
53. De Munck J, Van Meerbeek B, Yoshida Y, Inoue S, Suzuki K, Lambrechts P. Four-year water degradation of a resinmodified glass-ionomer adhesive bonded to dentin. Eur J Oral Sci 2004; 112:73- 83.

54. Coutinho E, Yoshida Y, Inoue S, Fukuda R, Snauwaert J, Nakayama Y, De Munck J, Lambrechts P, Suzuki K, Van Meerbeek B. Gel phase formation at resin-modified glassionomer/tooth interfaces. J Dent Res. 2007; 86: 656-61.

55. Hoshika S, De Munck J, Sano H, Sidhu SK, Van Meerbeek B. Effect of Conditioning and Aging on the Bond Strength and Interfacial Morphology of Glass-ionomer Cement Bonded to Dentin. J Adhes Dent. 2015;17:141-6.

56. Hewlett ER, Caputo AA, Wrobel DC. Glass ionomer bond strength and treatment of dentin with polyacrylic acid. J Prosthet Dent. 1991;66:767-72.

57. Pereira P, Yamada T, Tei R, Tagami J. Bond strength and interface micromorphology of an improved resin-modified glass ionomer cement. American journal of dentistry 1997;10:128-132.

58. Inoue S, Abe Y, Yoshida Y, De Munck J, Sano H, Suzuki K, Lambrechts P, Van Meerbeek B. Effect of conditioner on bond strength of glass ionomer adhesive to dentin/enamel with and without smear layer interposition. Oper Dent. 2004;29:685-92.

59. Breschi L, Mazzoni A, Ruggeri A, Cadenaro M, Di Lenarda R, Dorigo E. Dental adhesion review: aging and stability of the bonded interface. Dent Mater. 2008;24:90-101.

60. Lussi A, Jaeggi $\mathrm{T}$, Zero T. The role of diet in the aetiology of dental erosion. Caries Research. 2004; 38:34-44.

61. Ehlen LA, Marshall TA, Qian F, Wefel JS, Warren JJ. Acidic beverages increase the risk of in vitro tooth erosion. Nut Res. 2008;28:299-303.

62. Rios D, Honório HM, Magalhães AC, Wiegand A, Andrade Moreira Machado MA, Buzalaf MA. Light cola drink is less erosive than the regular one: an in situ/ex vivo study. J Dent. 2009;37:163-6.

63. Turssi CP, Hara AT, Serra MC, Rodrigues Jr AL. 2002. Effect of storage media upon the surface micromorphology of resin-based restorative materials. Journal of Oral Rehabilitation. 2002; 29:864-71.

64. de Gee AJ, van Duinen RN, Werner A, Davidson CL: Early and long-term wear of conventional and resinmodified glass ionomers. Journal of Dental, Research, 1996;75:1613-9.

65. Prakki A, Cilli R, Mondelli RF, Kalachandra S, Pereira JC. Influence of $\mathrm{pH}$ environment on polymer based dental material properties. J Dent. 2005;33:91-8. 